\title{
Experimental Study on the Effects of Compression Parameters on Molding Quality of Dried Fish Floss
}

\author{
Hongmei Xu, Li Zong, Ling Li, and Jing Zhang \\ College of Engineering and Technology, Huazhong Agricultural University, \\ Wuhan 430070, China \\ xhm790912@163.com
}

\begin{abstract}
Taking the molding block thickness, relaxation ratio and shatter resistance as evaluation indicators, the effects of compression parameters, which include mold form, compressive force, pressure-holding time and loading rate, on molding block quality of fish floss were investigated by means of single factor and orthogonal test. The results showed that: 1) the mold form, compressive force, pressure-holding time and loading rate have great impact on the molding block thickness, and the block thickness decreases with the increase of compressive force and pressure-holding time; 2) the loading rate and pressureholding time affect the relaxation ratio of molding block significantly; 3 ) the pressure-holding time highly affects the shatter resistance of molding block, and the shatter resistance will be greatly improved after a period of pressure holding;4) the interactions between different parameters have no significant effect on the molding block quality. The results can provide references for the development of compression molding equipment and selection of the technique parameters.
\end{abstract}

Keywords: Compression Molding, Technique Parameters, Molding Quality, Relaxation Ratio, Shatter Resistance.

\section{Introduction}

Dried fish floss is a kind of fish product, which is made with delicate techniques such as cooking, meat picking, seasoning, squeezing, frying etc. The compression molding is to suppress the loose dried fish floss under external force. As a result, the volume of dried fish floss decreases, while the density increases.

At present, the research of compression molding mainly focuses on the compression molding of agricultural material, such as food, biomass, and so on. Regarding the relationship between the physical characteristics of materials, compression parameters and the quality of molding block, many research results and conclusions have been achieved[1-4]. However, the research on the compression molding of meat product, such as fish floss, is less involved.

Taking the salted and dried fish floss as the research object, the effects of compression parameters, which include mold form, compressive force, pressure-holding time and loading rate, on molding block quality of fish floss were investigated by means of single factor and orthogonal test. On the basis of this, the reasonable mold form, loading 
method and pressure-holding time were determined. The results can provide references for the development of compression molding equipment and selection of the technique parameters.

\section{Materials and Devices}

\subsection{Materials}

For this experiment, the salted and dried chub was broken into fish floss by a highspeed meatball machine.

\subsection{Devices}

A set of steel cylinder mold (Fig.1) with a pressure device was designed for the experiment. As shown in figure1, the part 2 and 3 respectively denote the punch and die of the mold.

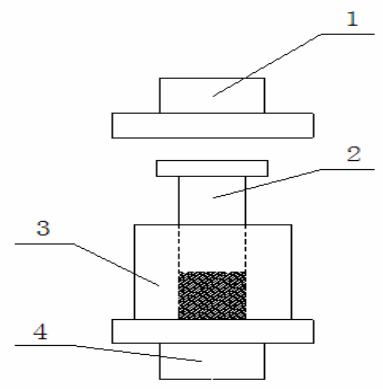

Fig. 1. Sketch map of the mold

1. Upper platen 2. Punch 3. Die 4. Bottom platen

\subsection{Instruments}

(1) RGT2000-10 Microcomputer Control Electronic Universal Testing Machine Maximum load: 5KN; Test speed: 0.01-500mm/min; Manufacturer: Shenzhen Reger instrument Co., Ltd.

(2) YXQ.SG41.280 Portable Pressure Steam Sterilizer

Maximum working pressure: $0.15 \mathrm{MPa}$; Maximum working temperature: $126^{\circ} \mathrm{C}$; Net weight: $15.5 \mathrm{~kg}$.

(3) 202-00 Desktop Electric Oven

Temperature fluctuation: $0.1{ }^{\circ} \mathrm{C}$; Temperature range: $50-250{ }^{\circ} \mathrm{C}$; Manufacturer: Tianjin Taisite instrument Co., Ltd.

(4) HSN-22 high-speed meatball machine

Productivity: $80 \mathrm{~kg} / \mathrm{h}$; Power: $2.2 \mathrm{kw}$. 


\section{Methods}

The compression molding test was conducted on the RGT2000-10 computercontrolled electronic universal testing machine. A set of steel cylinder molds with the square and round hole were designed for the experiment.

During the measurement, the die was placed on the bottom platen. The dried fish floss was first metered into the die, and then the punch was inserted in the die. Afterwards, adjust the location of the upper and bottom platen, so that the upper platen just contacts with the punch.

In order to investigate the effects of compression parameters on molding quality of fish floss, the single-factor experiments were successively carried out on the conditions of different mold forms, compressive forces, loading rates and pressure-holding times, while the physical characteristics, such as moisture content and particle size, remain the same. Additionally, the effects of interaction of loading rate with compressive force and pressure-holding time on the quality of molding block were determined by means of orthogonal test.

\section{Results and Discussion}

\subsection{Effect of Mold Form on the Quality of Molding Block}

In order to investigate the effect of mold form on the compression molding quality of fish floss, the single-factor experiments were carried out in the case of constant compressive force(3Mpa), pressure-holding time(60s) and loading $\operatorname{rate}(30 \mathrm{~mm} / \mathrm{min})$, while the mold form is various. Specifically, the molds with the square or round inner hole, which is $25 \mathrm{~mm}$ and $30 \mathrm{~mm}$ in diameter or edge, were employed to carry out the single-factor experiments of four levels.

\subsubsection{Effect of Mold Form on the Thickness of Molding Block}

Table 1 shows the variance analysis results of molding block thickness when using different mold forms. As shown in the table, when the significance level $\alpha$ is equal to 0.05 , F-statistics is greater than the critical value $F_{\alpha}$, and the P-value, which denotes the probability of having no significant effect on the experimental results, is greater than 0.01 ,but less than 0.05 . The results indicate that mold form affects the thickness of molding block significantly. Additionally, observe the mean value of molding block thicknesses, it can be found that the thickness of molding block is relatively small when using the mold with the diameter of $30 \mathrm{~mm}$.

Table 1. Variance analysis of the molding block thickness when using different mold forms

\begin{tabular}{|ccccccc|}
\hline $\begin{array}{c}\text { Error } \\
\text { source }\end{array}$ & SS & df & MS & F & $\begin{array}{c}\text { P } \\
\text { value }\end{array}$ & $\mathrm{F}_{\alpha}$ \\
\hline Inter & 0.242 & 3 & 0.081 & 5.093 & 0.019 & 3.587 \\
Intra & 0.174 & 11 & 0.016 & & & \\
Total & 0.416 & & & & & \\
\hline
\end{tabular}

Note: Inter shows "Inter-group error"; Intra shows "Intra-group error". 


\subsubsection{Effect of Mold Form on the Relaxation Ratio of Molding Block}

Table 2 shows the variance analysis results of molding block relaxation ratio when using different mold forms. When the significance level $\alpha$ is equal to $0.05, \mathrm{~F}$-statistics is less than $F_{\alpha}$, and P-value is greater than 0.05 . The results clearly show that mold form has no significant effect on the relaxation ratio of molding block.

Table 2. Variance analysis of the molding block relaxation ratio when using different mold forms

\begin{tabular}{|ccccccc|}
\hline $\begin{array}{c}\text { Error } \\
\text { source }\end{array}$ & $\mathrm{SS}$ & $\mathrm{df}$ & $\mathrm{MS}$ & $\mathrm{F}$ & $\begin{array}{c}\mathrm{P} \\
\text { value }\end{array}$ & $\mathrm{F}_{\alpha}$ \\
\hline Inter & 0.003 & 3 & 0.001 & 0.629 & 0.611 & 3.587 \\
Intra & 0.017 & 11 & 0.002 & & & \\
Total & 0.020 & & & & & \\
\hline
\end{tabular}

\subsubsection{Effect of Mold Form on the Shatter Resistance of Molding Block}

Table 3 shows the variance analysis results of molding block shatter resistance when using different mold forms. Since F-statistics is less than the critical value $F_{\alpha}$ $(\alpha=0.05)$, and P-value is greater than 0.05 , It is, therefore, believed that mold form does not affect the shatter resistance of molding block significantly.

Table 3. Variance analysis of the molding block shatter resistance when using different mold forms

\begin{tabular}{|ccccccc|}
\hline $\begin{array}{c}\text { Error } \\
\text { source }\end{array}$ & SS & df & MS & F & $\begin{array}{c}\mathrm{P} \\
\text { value }\end{array}$ & $\mathrm{F}_{\alpha}$ \\
\hline Inter & 0.0005 & 3 & 0.0002 & 1.601 & 0.245 & 3.587 \\
Intra & 0.0011 & 11 & 0.0001 & & & \\
Total & 0.0016 & & & & & \\
\hline
\end{tabular}

\subsection{Effect of Compressive Force on the Quality of Molding Block}

In the case of constant mold inner diameter $(30 \mathrm{~mm})$, pressure-holding time $(60 \mathrm{~s})$, and loading rate $(30 \mathrm{~mm} / \mathrm{min})$, the compression molding test was performed to investigate the effects of compressive force on the quality of molding block. In order to reduce the measurement error, the compression experiment was repeated three times at each level of compressive force, corresponding to $1 \mathrm{MPa}, 2 \mathrm{MPa}, 3 \mathrm{MPa}, 4 \mathrm{MPa}$, and $5 \mathrm{MPa}$.

\subsubsection{Effect of Compressive Force on the Thickness of Molding Block}

Table 4 and Table 5 show the average and variance of molding block thickness when using different compressive forces. At the significance level of 0.01, F-statistics is greater than $F_{\alpha}(\alpha=0.01), \mathrm{P}$-value is less than 0.01. Apparently, the compressive force has a great impact on the thickness of molding block. In addition to this, observe the mean value of molding block thicknesses, it can be found that the greater the compressive force is, the thicker the molding block is, and when the compressive force 
increases from $1 \mathrm{MPa}$ to $2 \mathrm{MPa}$,the molding block thickness decreases significantly. Furthermore, the relationship between compressive force and molding block thickness can be represented mathematically as follows:

$$
y=5.67+0.73 / x
$$

where the variable $y$ and $x$ respectively denote the molding block thickness and compressive force.

Table 4. Average and variance of the molding block thickness when using different compressive forces

\begin{tabular}{|ccccc|}
\hline Group & Point & Sum & Average & Variance \\
\hline $1 \mathrm{MPa}$ & 3 & 19.23 & 6.41 & 0.003 \\
$2 \mathrm{MPa}$ & 3 & 17.98 & 5.99 & 0.002 \\
$3 \mathrm{MPa}$ & 3 & 17.95 & 5.98 & 0.013 \\
$4 \mathrm{MPa}$ & 3 & 17.55 & 5.85 & 0.003 \\
$5 \mathrm{MPa}$ & 3 & 17.40 & 5.80 & 0.018 \\
\hline
\end{tabular}

Table 5. Variance analysis of the molding block thickness when using different compressive forces

\begin{tabular}{|ccccccc|}
\hline $\begin{array}{c}\text { Error } \\
\text { source }\end{array}$ & SS & df & MS & $\mathrm{F}$ & $\begin{array}{c}\mathrm{P} \\
\text { value }\end{array}$ & $\mathrm{F}_{\alpha}$ \\
\hline Inter & 0.692 & 4 & 0.173 & 23.148 & $4.85 \mathrm{E}-5$ & 3.48 \\
Intra & 0.075 & 10 & 0.007 & & & \\
Total & 0.767 & & & & & \\
\hline
\end{tabular}

\subsubsection{Effect of Compressive Force on the Relaxation Ratio of Molding Block}

Table 6 shows the variance analysis results of molding block relaxation ratio when using different compressive forces. At the significance level of 0.05 , F-statistics is less than $F_{\alpha}(\alpha=0.05)$, P-value is greater than 0.05 . Therefore, it can be concluded that the compressive force has no significant effect on the relaxation ratio of molding block.

Table 6. Variance analysis of the molding block relaxation ratio when using different compressive forces

\begin{tabular}{|ccccccc|}
\hline $\begin{array}{c}\text { Error } \\
\text { source }\end{array}$ & SS & df & MS & $\mathrm{F}$ & $\begin{array}{c}\text { P } \\
\text { value }\end{array}$ & $\mathrm{F}_{\alpha}$ \\
\hline Inter & 0.003 & 4 & 0.0007 & 0.737 & 0.587 & 3.48 \\
Intra & 0.009 & 10 & 0.0009 & & & \\
Total & 0.012 & & & & & \\
\hline
\end{tabular}

\subsubsection{Effect of Compressive Force on the Shatter Resistance of Molding Block}

Table 7 shows the variance analysis results of molding block shatter resistance when using different compressive forces. When the significance level $\alpha$ is equal to 0.05 , 
Table 7. Variance analysis of the molding block shatter resistance when using different compressive forces

\begin{tabular}{|ccccccc|}
\hline $\begin{array}{c}\text { Error } \\
\text { source }\end{array}$ & SS & df & MS & F & $\begin{array}{c}\text { P } \\
\text { value }\end{array}$ & $\mathrm{F}_{\alpha}$ \\
\hline Inter & $5.39 \mathrm{E}-5$ & 4 & $1.35 \mathrm{E}-5$ & 2.25 & 0.136 & 3.48 \\
Intra & $5.99 \mathrm{E}-5$ & 10 & $5.99 \mathrm{E}-6$ & & & \\
Total & 0.0001 & & & & & \\
\hline
\end{tabular}

F-statistics is less than $F_{\alpha}(\alpha=0.05)$, P-value is greater than 0.05.It is clear that the compressive force has no significant effect on the shatter resistance of molding block.

\subsection{Effect of Pressure-Holding Time on the Quality of Molding Block}

In the case of constant mold inner diameter $(30 \mathrm{~mm})$, compressive force (3MPa), and loading rate $(30 \mathrm{~mm} / \mathrm{min})$, the compression molding test was performed to investigate the effects of pressure-holding time on the quality of molding block. In order to reduce the measurement error, the compression experiment was repeated three times at each level of pressure-holding time, corresponding to $0 \mathrm{~s}, 30 \mathrm{~s}, 60 \mathrm{~s}, 90 \mathrm{~s}$, and $120 \mathrm{~s}$.

\subsubsection{Effect of Pressure-Holding Time on the Thickness of Molding Block}

Table 8 and Table 9 show the average and variance of molding block thickness when using different pressure-holding times. At the significance level of 0.01 , F-statistics is greater than $F_{\alpha}(\alpha=0.01), \mathrm{P}$-value is less than 0.01 .The results show that the pressureholding time affects the thickness of molding block significantly. The longer the pressure-holding time, the thinner the molding block. Specifically, when the pressureholding time varies in the range of $0 \mathrm{~s} \sim 30 \mathrm{~s}$, the increase of pressure-holding time usually results in the great decrease of molding block thickness. After that, the thickness of molding block doesn't subject to the pressure-holding time and slightly decreases. Furthermore, the thickness basically maintains constant when the pressure-holding time exceeds 90 seconds.

The variation between pressure-holding time and molding block thickness can be represented by the following equation:

$$
y=-486.8+4572.1 / x
$$

where the variable $y$ and $x$ respectively denote the molding block thickness and pressure-holding time.

Table 8. Average and variance of the molding block thickness when using different pressureholding times

\begin{tabular}{|ccccc|}
\hline Group & Point & Sum & Average & Variance \\
\hline $0 \mathrm{~s}$ & 3 & 23.62 & 7.87 & 0.011 \\
$30 \mathrm{~s}$ & 3 & 18.84 & 6.28 & 0.005 \\
$60 \mathrm{~s}$ & 3 & 18.75 & 6.25 & 0.001 \\
$90 \mathrm{~s}$ & 3 & 17.77 & 5.92 & 0.012 \\
$120 \mathrm{~s}$ & 3 & 17.51 & 5.85 & 0.000 \\
\hline
\end{tabular}


Table 9. Variance analysis of the molding block thickness when using different pressureholding times

\begin{tabular}{|ccccccc|}
\hline $\begin{array}{c}\text { Error } \\
\text { source }\end{array}$ & $\mathrm{SS}$ & $\mathrm{df}$ & $\mathrm{MS}$ & $\mathrm{F}$ & $\begin{array}{c}\mathrm{P} \\
\text { value }\end{array}$ & $\mathrm{F}_{\alpha}$ \\
\hline Inter & 8.179 & 4 & 2.045 & 355.09 & 0.000 & 3.48 \\
Intra & 0.058 & 10 & 0.006 & & & \\
Total & 8.236 & & & & & \\
\hline
\end{tabular}

\subsubsection{Effect of Pressure-Holding Time on the Relaxation Ratio of Molding Block}

Table 10 displays the variance analysis results of molding block relaxation ratio when using different pressure-holding times. At the significance level of 0.01 , F-statistics is greater than $F_{\alpha}(\alpha=0.01)$, P-value is less than 0.01. It's clear that the pressure-holding time has great impact on the relaxation ratio of molding block. Beyond that, observe the mean value of molding block relaxation ratio, it can be found that the molding block relaxation ratio will be greatly improved after a period of pressure holding. The results suggest that, at the beginning of pressure holding, the compressive force increases to a maximum value, which usually results in great internal stress in the interior of molding block, and pressure holding can balance a large part of internal stress.

Table 10. Variance analysis of the molding block relaxation ratio when using different pressure-holding times

\begin{tabular}{|ccccccc|}
\hline $\begin{array}{c}\text { Error } \\
\text { source }\end{array}$ & SS & df & MS & $\mathrm{F}$ & $\begin{array}{c}\mathrm{P} \\
\text { value }\end{array}$ & $\mathrm{F}_{\alpha}$ \\
\hline Inter & 0.028 & 4 & 0.0070 & 355.09 & 0.000 & 3.48 \\
Intra & 0.002 & 10 & 0.0003 & & & \\
Total & 0.030 & & & & & \\
\hline
\end{tabular}

\subsubsection{Effect of Pressure-Holding Time on the Shatter Resistance of Molding Block}

Table 11 displays the variance analysis results of molding block shatter resistance when using different pressure-holding times. At the significance level of $0.05, \mathrm{~F}$ statistics is greater than $F_{\alpha}(\alpha=0.05)$, P-value is greater than 0.01 , but less than 0.05 . The results suggest that pressure-holding time affects the shatter resistance of molding block significantly. Observe the mean value of molding block shatter resistance, it can

Table 11. Variance analysis of the molding block shatter resistance when using different pressure-holding times

\begin{tabular}{|ccccccc|}
\hline $\begin{array}{c}\text { Error } \\
\text { source }\end{array}$ & SS & df & MS & F & $\begin{array}{c}\text { P } \\
\text { value }\end{array}$ & $\mathrm{F}_{\alpha}$ \\
\hline Inter & 2.141 & 4 & 0.535 & 4.297 & 0.028 & 3.48 \\
Intra & 1.246 & 10 & 0.125 & & & \\
Total & 3.387 & & & & & \\
\hline
\end{tabular}


be found that the molding block, with the pressure-holding time of $0 \mathrm{~s}$, is poor at the shatter resistance, and when the pressure-holding time is $30 \mathrm{~s}$, the molding block can achieve better shatter resistance.

\subsection{Effect of Loading Rate on the Quality of Molding Block}

In the case of constant mold inner diameter $(30 \mathrm{~mm})$, compressive force (3MPa), and pressure-holding time $(60 \mathrm{~s})$, the compression molding test was performed to investigate the effects of loading rate on the quality of molding block. In order to reduce the measurement error, the compression experiment was repeated three times at each level of loading rate, corresponding to $10 \mathrm{~mm} / \mathrm{min}, 20 \mathrm{~mm} / \mathrm{min}$, and $30 \mathrm{~mm} / \mathrm{min}$.

\subsubsection{Effect of Loading Rate on the Thickness of Molding Block}

Table 12 and Table 13 display the average and variance of molding block thickness when using different loading rates. At the significance level of 0.05 , F-statistics is greater than $F_{\alpha}(\alpha=0.05)$, P-value is greater than 0.01 , but less than 0.05 . The results suggest that loading rate has great impact on the thickness of molding block. Figure 2 represents the relationship between loading rate and molding block thickness. As shown in the figure, when the loading rate increases from $10 \mathrm{~mm} / \mathrm{min}$ to $30 \mathrm{~mm} / \mathrm{min}$, the thickness of molding block decreases firstly and then increases.

Table 12. Average and variance of the molding block thickness when using different loading rates

\begin{tabular}{|ccccc|}
\hline Group & Point & Sum & Average & Variance \\
\hline $10 \mathrm{~mm} / \mathrm{min}$ & 3 & 17.69 & 5.90 & 0.007 \\
$20 \mathrm{~mm} / \mathrm{min}$ & 3 & 17.43 & 5.81 & 0.008 \\
$30 \mathrm{~mm} / \mathrm{min}$ & 3 & 18.26 & 6.09 & 0.003 \\
\hline
\end{tabular}

Table 13. Variance analysis of the molding block thickness when using different loading rates

\begin{tabular}{|ccccccc|}
\hline $\begin{array}{c}\text { Error } \\
\text { source }\end{array}$ & SS & df & MS & $\mathrm{F}$ & $\begin{array}{c}\mathrm{P} \\
\text { value }\end{array}$ & $\mathrm{F}_{\alpha}$ \\
\hline Inter & 0.120 & 2 & 0.060 & 10.814 & 0.010 & 5.14 \\
Intra & 0.033 & 6 & 0.006 & & & \\
Total & 0.153 & & & & & \\
\hline
\end{tabular}

\subsubsection{Effect of Loading Rate on the Relaxation Ratio of Molding Block}

Table 14 and Table 15 display the average and variance of molding block relaxation ratio when using different loading rates. At the significance level of 0.05 , F-statistics is greater than $F_{\alpha}(\alpha=0.05), \mathrm{P}$-value is greater than 0.01 , but less than 0.05 . The results suggest that loading rate affects the relaxation ratio of molding block significantly. 


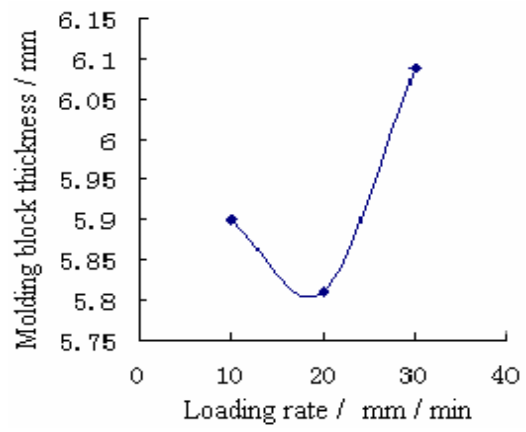

Fig. 2. Relationship between loading rate and molding block thickness

Table 14. Average and variance of the molding block relaxation ratio when using different loading rates

\begin{tabular}{|ccccc|}
\hline Group & Point & Sum & Average & Variance \\
\hline $10 \mathrm{~mm} / \mathrm{min}$ & 3 & 1.036 & 0.345 & 0.0002 \\
$20 \mathrm{~mm} / \mathrm{min}$ & 3 & 0.868 & 0.289 & 0.0004 \\
$30 \mathrm{~mm} / \mathrm{min}$ & 3 & 0.943 & 0.314 & 0.0002 \\
\hline
\end{tabular}

Table 15. Variance analysis of the molding block relaxation ratio when using different loading rates

\begin{tabular}{|ccccccc|}
\hline $\begin{array}{c}\text { Error } \\
\text { source }\end{array}$ & SS & df & MS & $\mathrm{F}$ & $\begin{array}{c}\mathrm{P} \\
\text { value }\end{array}$ & $\mathrm{F}_{\alpha}$ \\
\hline Inter & 0.005 & 2 & 0.0024 & 10.694 & 0.011 & 5.14 \\
Intra & 0.001 & 6 & 0.0002 & & & \\
Total & 0.006 & & & & & \\
\hline
\end{tabular}

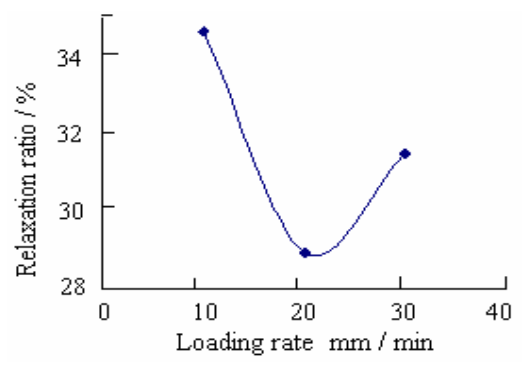

Fig. 3. Relationship between loading rate and relaxation ratio

Figure 3 represents the relationship between loading rate and relaxation ratio. As shown in the figure, when the loading rate increases from $10 \mathrm{~mm} / \mathrm{min}$ to $30 \mathrm{~mm} / \mathrm{min}$, the relaxation ratio of molding block gradually decreases firstly and then increases. 


\subsubsection{Effect of Loading Rate on the Shatter Resistance of Molding Block}

Table 16 displays the variance analysis results of molding block shatter resistance when using different loading rates. At the significance level of 0.05 , F-statistics is less than $F_{\alpha}(\alpha=0.05), \mathrm{P}$-value is greater than 0.05 . It can be concluded that the loading rate does not affect the shatter resistance of molding block significantly.

Table 16. Variance analysis of the molding block shatter resistance when using different loading rates

\begin{tabular}{|ccccccc|}
\hline $\begin{array}{c}\text { Error } \\
\text { source }\end{array}$ & SS & df & MS & F & $\begin{array}{c}\text { P } \\
\text { value }\end{array}$ & $\mathrm{F}_{\alpha}$ \\
\hline Inter & $1.32 \mathrm{E}-5$ & 2 & $6.60 \mathrm{E}-6$ & 2.77 & 0.141 & 5.14 \\
Intra & $1.43 \mathrm{E}-5$ & 6 & $2.38 \mathrm{E}-6$ & & & \\
Total & $2.75 \mathrm{E}-5$ & & & & & \\
\hline
\end{tabular}

\subsection{Effect of Interaction on the Quality of Molding Block}

As discussed above, loading rate, compressive force and pressure-holding time are the important technologic parameters in the process of compression molding. Taking the three parameters as experimental factors, the orthogonal tests were designed to explore whether there were interactions between these factors, and determine their major-minor sequence according to the effects on the molding block quality. For convenience, the factors of loading rate, compressive force and pressure-holding time were respectively marked as $\mathrm{A}, \mathrm{B}$, and $\mathrm{C}$. In addition, the levels of factor $\mathrm{A}, \mathrm{B}$ and $\mathrm{C}$ are 10 $\mathrm{mm} / \mathrm{min}, 30 \mathrm{~mm} / \mathrm{min}, 1 \mathrm{MPa}, 3 \mathrm{MPa}, 30 \mathrm{~s}$ and $90 \mathrm{~s}$ in turn.

\subsubsection{Effect of Interaction on the Thickness of Molding Block}

Table 17 displays the variance analysis results of molding block thickness when the interactions between the three factors are taken into account. As shown in the table, since $\mathrm{MS}_{\mathrm{A} \times \mathrm{C}}$ is less than $\mathrm{MS}_{\mathrm{e}}$, the interaction between $\mathrm{A}$ and $\mathrm{C}$ has minor effect on the molding block thickness, so it can be subsumed in the term of error (e), and bring

Table 17. Variance analysis of the molding block thickness when considering the interactions between the factors

\begin{tabular}{|cccccc|}
\hline $\begin{array}{c}\text { Error } \\
\text { source }\end{array}$ & $\mathrm{SS}$ & $\mathrm{df}$ & $\mathrm{MS}$ & $\mathrm{F}$ & Significance \\
\hline $\mathrm{A}$ & 0.143 & 1 & 0.143 & 233.65 & $* *$ \\
$\mathrm{~B}$ & 2.195 & 1 & 2.195 & 3582.88 & $* *$ \\
$\mathrm{~A} \times \mathrm{B}$ & 0.007 & 1 & 0.007 & 10.80 & \\
$\mathrm{C}$ & 0.270 & 1 & 0.270 & 441.00 & $* *$ \\
$\mathrm{~A} \times \mathrm{C}$ & 0.001 & 1 & 0.001 & & \\
$\mathrm{~B} \times \mathrm{C}$ & 0.002 & 1 & 0.002 & 3.45 & \\
$\mathrm{e}$ & 0.001 & 1 & 0.001 & & \\
$\mathrm{e}^{\Delta}$ & 0.0012 & 2 & 0.0006 & & \\
\hline
\end{tabular}


about the new term of error $\left(\mathrm{e}^{\Delta}\right)$.The results suggest that the three factors have significant effect on the thickness of molding block, and the major-minor sequence is $\mathrm{B}, \mathrm{C}$, and A. However, the interactions between the factors don't affect the thickness of molding block significantly.

\subsubsection{Effect of Interaction on the Relaxation Ratio of Molding Block}

Table 18 displays the variance analysis results of molding block relaxation ratio when the interactions between the factors are taken into account. As shown in the table, the factors of $\mathrm{A}, \mathrm{B}, \mathrm{C}$ and their interactions have no significant effect on the relaxation ratio of molding block.

Table 18. Variance analysis of the molding block relaxation ratio when considering the interactions between the factors

\begin{tabular}{|cccccc|}
\hline $\begin{array}{c}\text { Error } \\
\text { source }\end{array}$ & SS & df & MS & F & Significance \\
\hline $\mathrm{A}$ & 10727.2 & 1 & 10727.2 & 1.01 & \\
$\mathrm{~B}$ & 10678.5 & 1 & 10678.5 & 1.00 & \\
$\mathrm{~A} \times \mathrm{B}$ & 10652.0 & 1 & 10652.0 & 1.00 & \\
$\mathrm{C}$ & 10676.6 & 1 & 10676.6 & 1.00 & \\
$\mathrm{~A} \times \mathrm{C}$ & 10668.7 & 1 & 10668.7 & 1.00 & \\
$\mathrm{~B} \times \mathrm{C}$ & 10642.4 & 1 & 10642.4 & & \\
$\mathrm{e}$ & 10649.0 & 1 & 10649.0 & & \\
$\mathrm{e}^{\Delta}$ & 21291.3 & 2 & 10645.7 & & \\
\hline
\end{tabular}

\subsubsection{Effect of Interaction on the Shatter Resistance of Molding Block}

Table 19 displays the variance analysis results of molding block shatter resistance when the interactions between the factors are taken into account. As shown in the table, the factors and interactions don't affect the shatter resistance of molding block significantly.

Table 19. Variance analysis of the molding block shatter resistance when considering the interactions between the factors

\begin{tabular}{|cccccc|}
\hline $\begin{array}{c}\text { Error } \\
\text { source }\end{array}$ & SS & df & MS & F & Significance \\
\hline $\mathrm{A}$ & 77217.8 & 1 & 77217.8 & & \\
$\mathrm{~B}$ & 77221.5 & 1 & 77221.5 & 1.00 & \\
$\mathrm{~A} \times \mathrm{B}$ & 77217.8 & 1 & 77217.8 & & \\
$\mathrm{C}$ & 77221.2 & 1 & 77221.2 & 1.00 & \\
$\mathrm{~A} \times \mathrm{C}$ & 77217.7 & 1 & 77217.7 & & \\
$\mathrm{~B} \times \mathrm{C}$ & 77219.3 & 1 & 77219.3 & & \\
$\mathrm{e}$ & 77218.3 & 1 & 77218.3 & & \\
$\mathrm{e} \Delta$ & 308871.6 & 4 & 77217.90 & & \\
\hline
\end{tabular}




\section{Conclusions}

Taking the molding block thickness, relaxation ratio and shatter resistance as evaluation indicators, the effects of mold form, compressive force, pressure-holding time, loading rate and interactions between them on the block quality were investigated. The conclusions are summarized as follows:

1) Mold form affects the thickness of molding block significantly. For the four given molds, the thickness of molding block, compressed by the mold with the diameter of $30 \mathrm{~mm}$, is relatively small. Mold form has no significant effect on the relaxation ratio and shatter resistance.

2) Compressive force has great impact on the thickness of molding block. The thickness of molding block decreases with the increase of compressive force, and the greater the compressive force is, the smaller the thickness is. Compressive force does not affect the relaxation ratio and shatter resistance significantly.

3) Pressure-holding time has significant effect on the molding block thickness, relaxation ratio and shatter resistance. The longer the Pressure-holding time is, the smaller the thickness is. Specifically, when the pressure-holding time increases from 0 s to 30 s, its increase usually results in the great decrease of molding block thickness. After that, the block thickness doesn't subject to the pressure-holding time and slightly decreases. Furthermore, the thickness basically maintains constant when the pressure-holding time exceeds 90s. The molding block relaxation ratio will be improved after a period of pressure holding. However, when the pressure-holding time increases from 30 s to 120 s, the relaxation ratio almost remains the same. Likewise, after a period of pressure holding, the block shatter resistance will be greatly improved.

4) When the loading rate increases from $10 \mathrm{~mm} / \mathrm{min}$ to $30 \mathrm{~mm} / \mathrm{min}$, the molding block thickness and relaxation ratio vary considerably. Specifically, the molding block thickness and relaxation ratio gradually decreases firstly and then increases. Loading rate has no great effect on the shatter resistance of molding block.

5) Compressive force, pressure-holding time and loading rate affect the thickness of molding block significantly, and the major-minor sequence is pressureholding time, loading rate, and compressive force. The three factors have no significant effect on the relaxation ratio and shatter resistance. Additionally, the interactions don't affect the block quality.

\section{Acknowledgement}

This research was supported by Scientific Research Foundation of Huazhong Agricultural University for the Introduced Talents "Research on the Evaluation Index System of Rice Moisture for Safe Storage" under grant Nos. 52204-08079. 


\section{References}

1. Wang, J.Y., Zhao, G.J., Yang, Q.L.: Compression and permanent fixatian with heat treatment of China fir under water-saturated condition and air-dried condition. Journal of Beijing Forestry University 22(1), 72-75 (2000)

2. Sheng, K.C., Qian, X.Q., Wu, J.: Experimental studies on compressing chopped cotton stalks to high densities. Journal of Zhejiang University (Agriculture and Life Sciences) 29(2), 139-142 (2003)

3. Huang, G.X., Chen, L.J., Cao, J.: Briquetting mechanism and waterproof performance of bio-briquette. Journal of China Coal Society 33(7), 812-815 (2008)

4. Wang, J.X., Cai, H.Z.: Review on physical properties and forming technology of biomass fuel compressed. Journal of Agricultural Mechanization Research 1, 203-215 (2008) 